\title{
The journey from clinician to undergraduate medical educator involves four patterns of transformation
}

This article was published in the following Dove Press journal:

Advances in Medical Education and Practice

\author{
Efrain Riveros-Perez' \\ Jorge Rodriguez-Diaz ${ }^{2}$ \\ 'Obstetric Anesthesia Division, \\ Department of Anesthesiology and \\ Perioperative Medicine, Medical \\ College of Georgia, Augusta \\ University, Augusta, GA, USA; ${ }^{2}$ Surgery \\ Department, Clinica de los Andes, \\ Tunja, Colombia
}

Objectives: Traditionally, teaching is part of a clinician's job. Some practitioners recognize the teaching activity as rewarding. This study explored the ways clinical practitioners experience their journey from clinicians to medical teachers, analyzing their prior experiences of teaching and learning, conceptions of good teaching and learning, perceptions of learning environments, and finally, how those factors influence their approaches to teaching.

Methods: Data for phenomenographic analysis were collected through semi-structured interviews conducted in Spanish and administered to twelve clinical teachers in three medical schools in Colombia.

Results: Through sequential phases of analysis, we constructed a conceptual diagram to identify critical concepts, themes, and categories that describe patterns that clinicians adopt during their journey to become medical teachers. We identified two themes and four patterns that describe the journey from practitioner to medical teacher: the identity theme, referring to "what" practitioners showed as the object of the journey and the changing process theme referring to "how" participants adopt changes during the journey. We describe four patterns that describe the journey that physicians adopt when exposed to the experience of clinical teaching.

Conclusion: It is possible to identify two themes and to devise at least four patterns in ways of experiencing the journey to medical teacher. These patterns are not a fixed set of characteristics, but rather a spectrum of experiences. Taking into consideration the professional identity of clinical teachers and the path of their teaching process change, it might be possible to devise better strategies for teaching development activities.

Keywords: medical education, medical teacher, teaching experience

\section{Background}

Institutions of higher education claim undergraduate education as their priority. Their purpose is to facilitate students' learning, to raise understanding, and to develop abilities and attitudes that will equip them not only to respond to an unknown world but also to shape it. High-quality education demands teaching improvement in order to make formation more relevant in a constantly changing world. On the other hand, as concluded by Kember and Kwan, ${ }^{1}$ fundamental changes in teaching quality are unlikely to happen without changing the teacher's conception of teaching.

Learning is structured around the complex interaction between teaching and learning approaches. Trigwell et $\mathrm{al}^{2}$ described approaches to teaching in terms of the teachers' intentions and strategies. Intentions range from a vague purpose to transfer information, to the aim to have students change their conceptions and understanding of the subject matter, while strategies are designed to serve that end. The teaching approach
Correspondence: Efrain Riveros-Perez Obstetric Anesthesia Division, Department of Anesthesiology and Perioperative Medicine, Medical College of Georgia at Augusta University, II 20 I5th Street BI-2144, Augusta, GA 30912, USA

E-mail eriverosperez@augusta.edu 
depends on two critical aspects: teachers' understanding of the subject matter and teachers' ultimate teaching goal. In addition, teachers enter the teaching-learning context with certain prior conceptions and experiences of teaching and learning that in conjunction with new learning situations produce a unique teaching conception that determines an individual teaching approach.

Teaching in medical schools integrates teacher and student factors and takes into consideration the aspects related to adult learning. In 1968, Malcolm Knowles proposed “a new label and a new technology" of adult learning to distinguish it from preadult schooling, coining the term "andragogy" to define "the art and science of helping adults learn" in contrast to the term "pedagogy," conceived as the art and science of helping children learn. ${ }^{3,4}$ Clinical teaching assumes the medical student as an adult learner.

Given the important role that clinical teaching plays in medical education, research studies examining the role of medical teachers are needed..$^{5}$ The vast majority of educational research in the medical field focuses on performance variables, despite the fact that significant variance of teaching effectiveness is due to relational variables. ${ }^{6}$ Teaching quality improvement results from a combination of personal teaching skills and introduction to innovative assessment techniques. ${ }^{7}$ The interplay between teaching abilities and student-teacher interaction is complex in clinical settings, as circumstances unique to health care systems impose constraints that make the teaching-learning cycle particularly challenging. Quality medical teaching is possible only when the clinician adopts the role of a teacher in the context of safe patient care.

A medical teacher's job has some unique characteristics. Medical teaching takes place on a part-time basis by clinical practitioners, in a work-related environment involving the active presence of patients. In addition, in some instances, teaching receives little attention and funding, due to organizational policies that effectively promote other activities related to direct patient care. ${ }^{8}$ In Colombia and other countries, the concept of the traditional teaching hospital has suffered transformations over the last decades, as public health policies leading to broad health care coverage and a general health system have prioritized patient care over medical education..$^{9,10}$

Doctors experience a transition from their role as clinical practitioners to medical teachers, when they practice in academic institutions. The goal of this study was to analyze the influence of medical teachers' conceptions of teaching and prior teaching experiences in clinical situations on the journey from a practitioner to a clinical teacher. We explored the ways clinical practitioners experience their journey from clinicians to medical teachers. We analyzed their prior teaching-learning experiences, their conceptions of good teaching and learning, their perceptions of learning environments, and the effects on their approaches to teaching.

\section{Methods}

We used phenomenography as a qualitative tool based on observation and experience, to identify different ways in which medical practitioners experience, conceptualize, perceive, and understand phenomena related to teaching. The subject matter of the study was the way in which practitioners as a group have experienced the journey from clinician to teacher. We focused on the practitioner's perceptions during the transformational journey. We identified and described a limited number of ways doctors have used to cope with the transition from clinician to medical teacher. We took into consideration individual aspects such as beliefs, experiences, expectations, and feedback after the performance of educational tasks.

After obtaining Institutional Review Board's approval from the involved medical schools (Universidad de Boyaca, Universidad Pedagogica y Tecnologica de Colombia, and Universidad Javeriana) and written informed consent from the participants, data were collected through semi-structured interviews administered to 12 clinical teachers of three medical schools in Colombia. Teachers were selected from a group of physicians affiliated to academic institutions. All of them were specialists in medicosurgical fields and had been working with medical students for at least 5 years. The interviews were interactive, aiming to explore the ways practitioners have adopted when teaching in clinical settings. The interviews aimed at discovering the interviewee's own framework of meanings and avoiding as much as possible imposition of the researcher's structure or assumptions. ${ }^{11}$ Interviews were completed when saturation of information was achieved. Excerpts from the interviews were used to identify categories and themes determining the patterns that describe the journey from clinician to medical teacher (Supplementary materials).

The interviews explored the following areas: teacher's conception of good clinical teaching and good clinical practice, strategies the teacher has employed in teaching and outcomes pursued by clinical practices undertaken by students, teacher's conceptions about the degree of responsibility medical students have of their learning process, and teacher's expectations regarding their teaching practices in terms of 
self-esteem. Box 1 shows the first-order questions included in the interview as well as additional questions aiming at exploring the effect of teaching on clinicians' perceptions.

Data consist of transcripts of interviews administered to academic physicians. Background of the interviewees included courses about teaching besides their clinical practice. Two women and ten men, specialists in general surgery, anesthesiology, critical care, gastroenterology, neurosurgery, pulmonology, psychiatry, orthopedic surgery, and dermatology, were interviewed. The interviews were conducted in Spanish. The files were deidentified and assigned a study number. Then, professional transcribers created a database for the analysis of deidentified and anonymous transcriptions. These documents were filed as Word documents (Microsoft Corporation, Redmond, WA, USA). Codes were assigned to each paragraph of the interview to identify answers to the study questions. The codes were used afterward to identify vignettes to support categories of analysis and themes. For analysis purposes, we identified critical concepts to further determine categories useful to label statements and paragraphs in the text that we considered meaningful.

\section{Results}

Data analysis and interpretation were divided into four phases, each having a different objective: familiarization with the data to have an overall impression, identification of similarities and differences in the statements, determination of descriptive categories for conceptions, and examination of the underlying structure of the system of categorization.

During phase 1, we found critical concepts that were used by interviewees as their way of sharing their experiences and beliefs regarding teaching. Box 2 shows the list of those critical concepts (elements teachers mentioned frequently during interviews). During phase 2, based on similarities among statements from different interviews, we grouped critical concepts into four categories: responsibility focus, teaching scholarship, teacher's mood, and satisfaction source. In phase 3, categories were conceptualized in terms of a continuum between two variations that were defined for each category (Table 1). Categories emerged as a group of characteristics linked to the aspects participants mentioned as related to the focus, the type of process, and actions on clinical teaching. Variations were conceived as two extreme points for each category.

The responsibility focus category refers to how interviewees discriminate their responsibilities between a practitioner and a teacher. "Dependent" variation of this characteristic means that teaching is conceived as part of clinical duties with no need to develop any other skills to teach. "Independent" variation on this category describes participants who were aware of differential responsibilities between teaching and medical practice. Teaching scholarship category refers to the intention of practitioners to teach and to develop teaching strategies. Alignment of intentions with actions and outcomes was the key concept used to explore this aspect. Variations ranged from those who intended to just transmit basic information using activities such as lectures and seminars (teacher-centered), to those who intend to transform the students' life acknowledging diversity in students as a challenge rather than as a difficulty (student-centered). For the former variation group, statements usually referred to providing students with knowledge and skills, necessary for evaluation as the only final result of educational processes. For the latter variation group, reflection is the most useful process. The interviewees are concerned about how students apply knowledge and are aware of the students' needs and learning challenges to fulfill the role of doctors in society. Teacher mood category refers to feelings teachers have about their teaching practices. Some participants in this group used explanatory statements to justify their drawbacks regarding

Box I Interview questions (first-order questions and additional questions exploring the effect of teaching on clinicians' perceptions)

First-order questions
I. What do you think good clinical practice and good clinical teaching are about?
2. How have you done your clinical teaching and why?
3. What type of outcomes have you pursued with your teaching activities?
4. What is your opinion about learning processes of your medical students?
5. How important are teaching activities for your professional development?

Additional questions

6. Regarding the conceptual change about teaching, what experiences or facts have triggered that changing process?

7. How can you describe the ideal role of medical teacher? Currently, how far are you from that ideal?

8. What has been the meaning of teaching in your professional life? How has teaching transformed your life?

9. Would you say something that can help us to understand the journey from clinician to medical teacher? 
Box 2 Critical concepts extracted from interview transcripts

\begin{tabular}{|l|}
\hline Critical concepts \\
Current teaching concept \\
Meaning of teaching \\
Teaching effectiveness \\
Teaching rewards \\
Enhancing teaching skills \\
Teaching strategies \\
Deficit justification \\
Teachers' goals \\
Changes in teaching methods \\
Teachers' role \\
Students' role \\
Patients' role \\
Teacher development \\
Teacher effectiveness \\
Reflection about teaching \\
\hline
\end{tabular}

Table I Categories and their variations within a continuum

\begin{tabular}{lll}
\hline Class & Category & Variation \\
\hline A & Responsibility focus & Dependent $\rightarrow$ independent \\
B & Teaching scholarship & Teacher-centered $\rightarrow$ student centered \\
C & Teachers' mood & Explaining away $\rightarrow$ transcending \\
D & Satisfaction source & From product $\rightarrow$ from process \\
\hline
\end{tabular}

teaching, finding reasons beyond their control (ie, institutionrelated, lack of pedagogical literacy, and workload) to blame for the inability to improve teaching quality (explain away variation). On the other end of the spectrum, there are teachers who consider teaching as a tool for them to accomplish professional and personal goals. We labeled this variation as transcending, as it intends to influence the students beyond the educational encounters. The last category, called satisfaction source, refers to self-esteem motivated by teaching and interacting with students. The variation spectrum includes the label, from product, when satisfaction originates from acknowledgment of the quality resulting from the teaching process, and the label, from process, when satisfaction is originated in personal learning during the teaching process.

During phase 4, characteristics and conceptions gathered during phases $1-3$ are analyzed in order to describe the journey practitioners have undertaken in doing medical teaching. We analyzed two aspects: the identity theme (what were the key aspects of teaching that changed during the journey) and the changing process theme (how did processes take place to generate the change) as described by Marton and Booth ${ }^{12}$ (Table 2). We used a diagram of categorization to define higher-order themes in addition to the critical concepts and categories identified during the first three phases, by means of systematic patterns. The diagram includes critical concepts from phase 1 (Box 2), categories from phases 2 and
Table 2 Themes and their variations within a continuum

\begin{tabular}{ll}
\hline Themes & Stages \\
\hline Teacher identity (what) & Clinician $\rightarrow$ educator \\
Changing process (how) & Preparation $\rightarrow$ action \\
\hline
\end{tabular}

3 (Table 1), and themes from phase 4 . Themes also have a spectrum of variation that we called stages. Teacher identity (what) theme ranges from a "clinician stage" focused on characteristics of the clinician role approaching teaching as a clinical task, to an "educator stage" focused on characteristics that reflect the educational role, creating a new professional identity. Changing process theme has the "preparation stage" on one end, reflecting the consciousness of some aspects that the practitioners wanted to change to the "action stage" displaying the actual undertaking of actions leading to changes in teaching motivated by participation in the educational journey. The teacher identity theme was constructed from two categories derived from critical concepts (phase 2) as shown in Figure 1. The changing process theme was conceived as a construct of two categories: teachers' mood and satisfaction source (Figure 2). During change induced by the educational journey, intentions are influenced by attitudes toward the object of the journey. Teachers' mood refers to the dominant feelings practitioners experienced linked to the transforming process to become good medical teachers. These feelings influence attitudes clinicians have taken to cope with the transformational journey. Satisfaction source variation can result from social pressure anticipating an educational outcome or from internal motivation to change the process of teaching. Stages for this theme have been labeled preparation and action stages. Preparation stage identifies those teachers who acknowledge intentions to adopt teaching changes but did not make statements regarding actual strategies to effect those changes in their teaching tasks. Action stage describes participants who recognized and adopted new practices that changed their overall teaching. Based on the stages for each of the two themes described above, we developed a matrix to display different patterns practitioners may adopt in their journey from clinician to medical teacher (Figure 3). A description of the identified patterns during the transformation journey from clinician to medical teacher is as follows. Each description centers on general profiles that characterize teachers based on the categories and their variations.

\section{Pattern 1: clinician identity and preparation for change:} It refers to participants who display elements of clinical identity and whose changing processes are at preparation stage. Their behavior in front of students is similar to their 


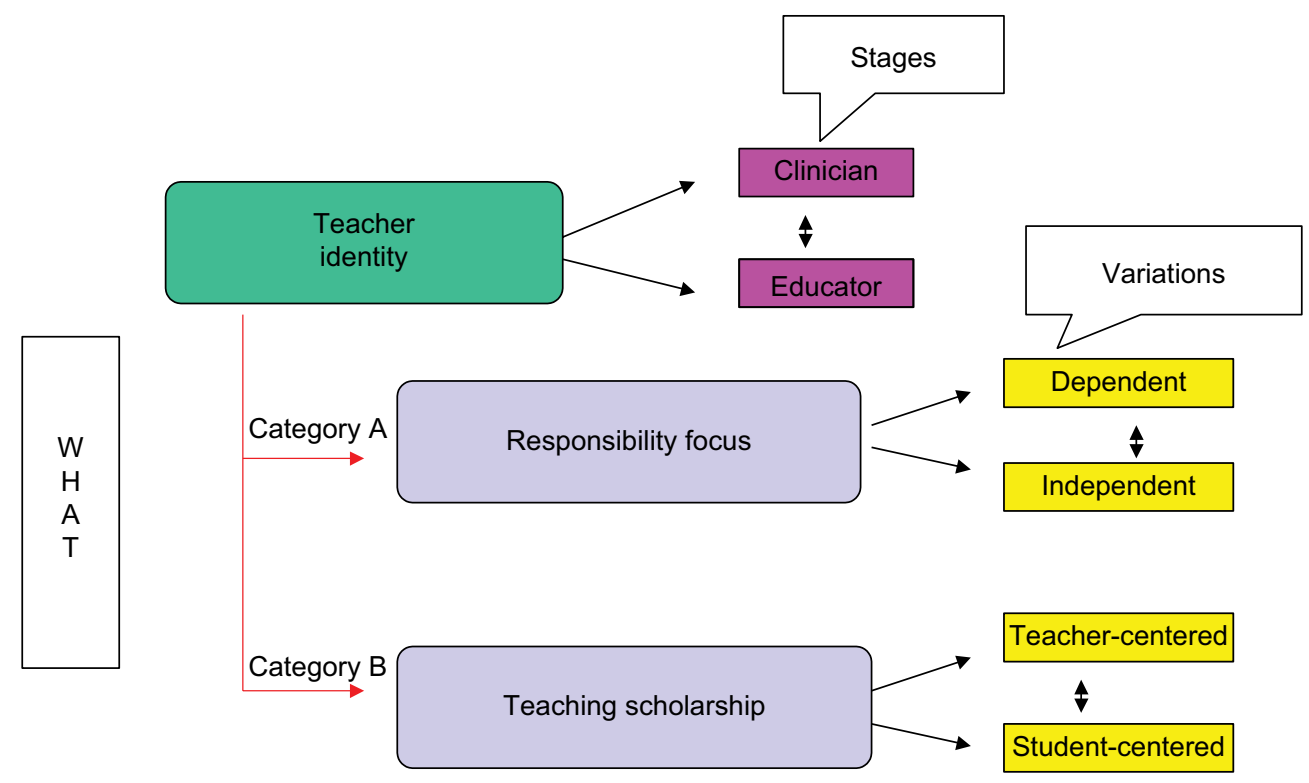

Figure I Structure of identity theme.

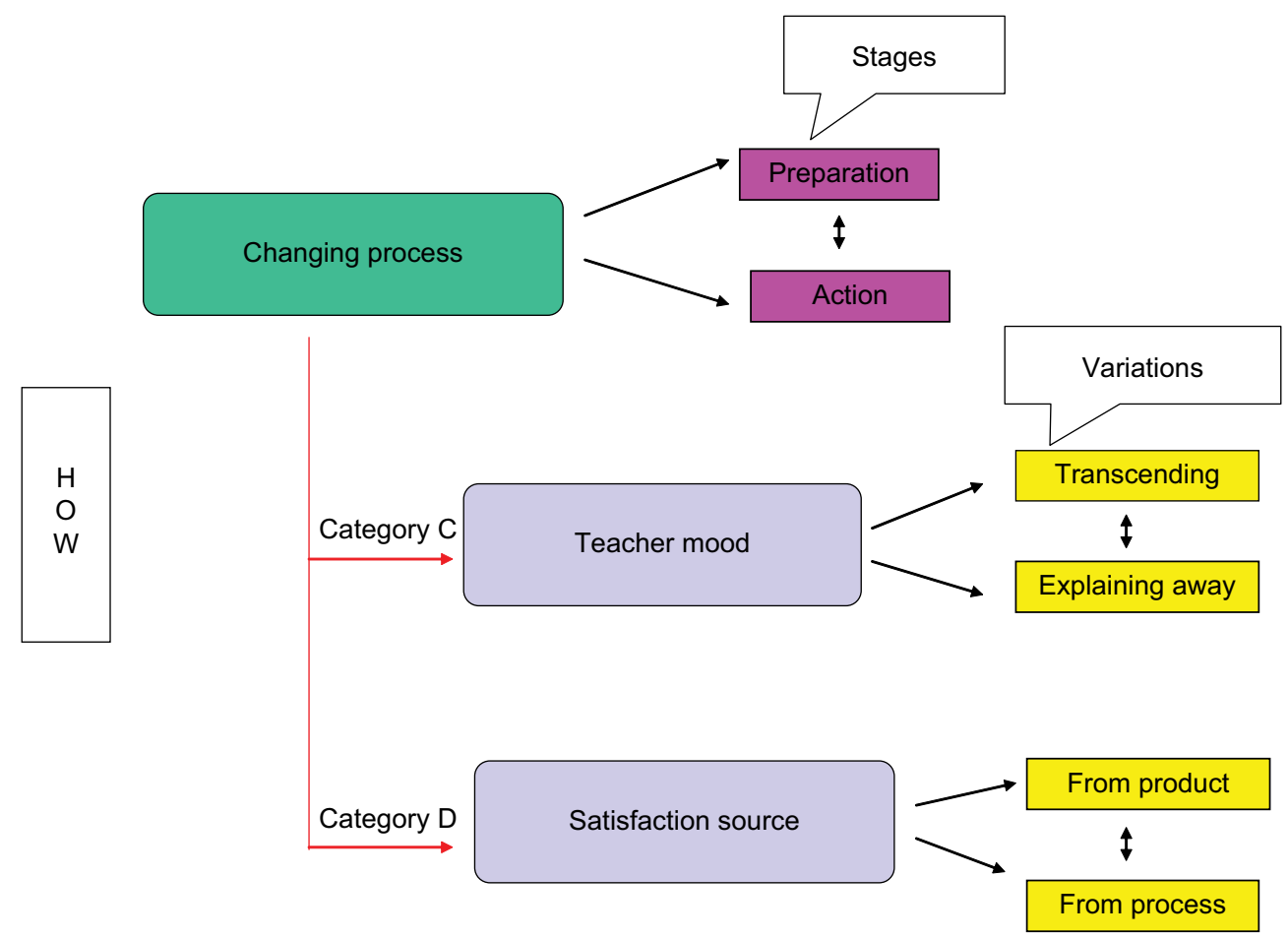

Figure 2 Structure of changing process theme.

behavior in front of patients. They are not aware of many of the aspects of teaching that should be taken into consideration in planning and implementing teaching activities. They feel that the responsibility in teaching is almost the same as physicians. In building pedagogical explanations for his/ her teaching activities, they usually construct the answer using words from clinical jargon and tend to search answers to pedagogical inquiries using clinical approaches. Their educational practices reflected their experiences as students in undergraduate and postgraduate courses. They should be located on the upper left quadrant in the matrix as they had elements from teacher-centered variation of category $B$ and elements from product variation of category D.

Pattern 2: educator identity and preparation for change: It refers to participants who are still on preparation stage in 


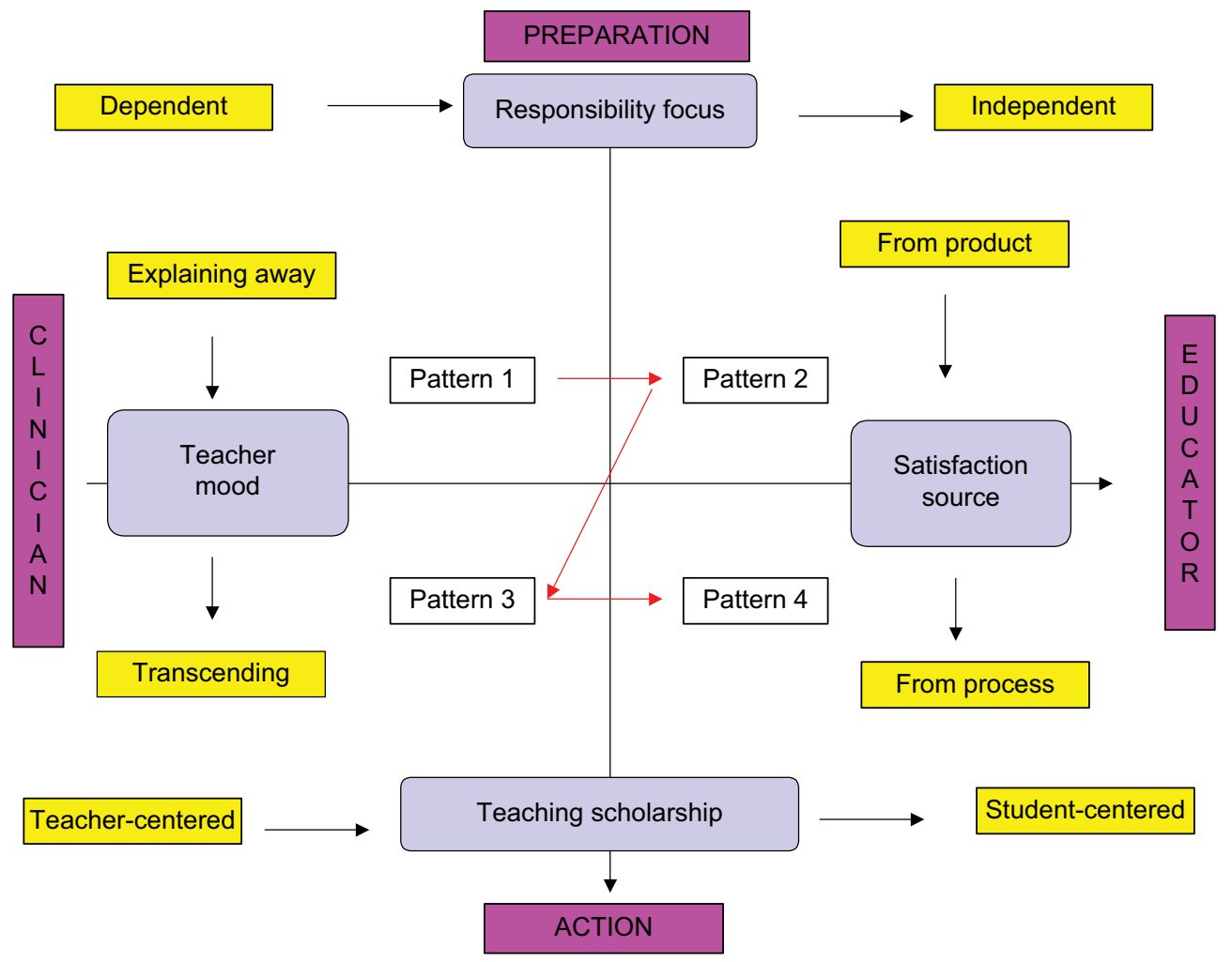

Figure 3 Patterns of experiencing the journey from clinician to medical teacher.

the changing process, but there are elements of educator identity. They are aware of most of the aspects of good medical teaching, and they acknowledge the importance of teaching for themselves and for the community. They are motivated to change and understand the benefits of that change. They are located on the upper right quadrant in the matrix, and the main elements come from explaining away variation of category $\mathrm{C}$ and from student-centered variation of category $\mathrm{B}$.

Pattern 3: clinician identity and action: It refers to participants who show elements of clinician stage of identity theme, but their process of change is evidenced by concrete activities. They are physicians who have gone into teaching activities without the awareness of the complexity of teaching, using their capabilities as clinicians, and approached teaching problems as clinical problems. They have tried a variety of strategies in teaching because they recognize the need to improve their teaching practice, but they are not able to properly explain the pedagogical rationale of these new activities. They are on the lower right quadrant of the matrix and contain elements from process variation of category $\mathrm{D}$ and dependent variation from category A.

Pattern 4: educator identity and action: It refers to participants who are showing elements of educator stage of identity and changing process themes. They are teachers who have identified the complexity of teaching and have approached teaching activities to enhance their pedagogical knowledge. They recognize the importance of aligning learning outcomes with activities and assessment. Their educational activities have their own time and approach, different from clinical activities. They have elements from transcending variation of category D and from independent variation of category A. They should be located on the lower left quadrant on the matrix.

These four patterns are the main elements to establish at what point on the grid a clinician could be in a particular moment during his or her journey. For instance, those clinicians who understand that their responsibility as educators is almost the same responsibility as clinicians should be located close to the left extreme in the grid on the horizontal axis. Conversely, those who understand that their responsibility as educators is independent of their responsibility as clinicians - responsibility focus category - should be moved to the right extreme on the horizontal axis, close to educator extreme of the identity theme. Those participants who had characteristics of the "explaining away" variation of teacher's mood category and also from "the product" variation of satisfaction source category should be located 
on the bottom of the vertical axis, close to the preparation stage of changing theme.

\section{Discussion}

The significance of this study resides on the ability to identify critical concepts, categories, themes, and patterns regarding the journey clinicians have experienced as a process of transformation and adaptation in doing medical teaching. Phenomenography is an interpretative approach that seeks to describe the qualitative finite number of ways of experiencing phenomena of interest. ${ }^{13}$ In this study, that phenomenon was the process of transformation and adaptation clinicians experience in two main aspects: the "how" of the process in terms of the stage of intentional change in which this process is brought about and the "what" regarding the main objects teachers have changed in terms of teachers' professional identity.

Teachers' professional identity was defined by Starr et al as a developmental process during which novices acquire specific knowledge and skills, develop new attitudes and values, and take on the self-concept associated with a new career role. ${ }^{14}$ Teaching development programs are important to help physicians achieve competence and strong teacher identity. This identity relies on internal and external elements. Internal elements are feelings and attitudes that lead to intrinsic satisfaction in one's professional role. External elements include a body of knowledge, rewards such as money or social recognition, and social support from colleagues or professional associations. The categories considered as part of the "what" aspect were the following: responsibility focus and scholarship of teaching. They were included as relevant topics to be changed because, as Irby pointed out, medical knowledge and patient care confer clinical credibility, while learning principles increase teaching credibility. ${ }^{15}$ Awareness of independence between an individual's responsibility as an educator and as a clinician is an important determinant on the journey we studied. Teaching scholarship and responsibility in teaching are aspects raising awareness. The concept of teaching scholarship ranges from the intention to transmit medical knowledge as the main goal in a clinical setting using teacher-centered approaches, to an intention to transform the student's life based on the acknowledgment of the student's prior conceptions. The teaching scholarship category takes into consideration aspects such as pedagogical knowledge and the focus (student-centered vs teacher-centered), having an impact on the way clinicians cope with their new role. The focus has been explored by Biggs, ${ }^{16}$ who states that good teaching (student-centered) makes students use higher cognitive level processes.
Starr et al identified seven elements that contribute to physicians' identity as teachers: feeling intrinsic satisfaction from teaching, having knowledge and skills about teaching, belonging to a group of teachers, feeling a responsibility to teach, sharing clinical expertise with learners, receiving rewards for teaching, and believing that being a physician means being a teacher. ${ }^{17}$ Stone et al, on the other hand, described four aspects of teacher identity: an underlying humanitarianism, familiarity with adult education principles and practices, appreciation for benefits and drawbacks of teaching, and the image of the self as a teacher. ${ }^{18}$ In our study, we included Starr's points into the structure of categorization. For instance, under responsibility focus, we identified aspects of "feeling intrinsic satisfaction," and under teaching scholarship, we found aspects of "having knowledge and skills about teaching." Variations on teachers' identity have been depicted by the theme teacher identity between the two stages: clinician to educator. The former was the starting point of the transformation journey, and the latter is its goal. Indeed, the changing process theme that was originated from teachers mood and satisfaction source categories also refers to some aspects that Starr et $\mathrm{al}^{17}$ and Stone et $\mathrm{al}^{18}$ have mentioned as related to teaching.

Intentional process change has been studied by Prochaska et al. ${ }^{19}$ They have described five stages: precontemplation, contemplation, preparation, action, and maintenance. The first three stages refer to becoming aware of the need for change. In this study, we used the term "preparation" in a slightly different sense. We grouped those participants who were aware of the need for adapting their clinical practice to clinical teaching, but lacking evidence of any change. Preparation, in Prochaska's model, refers to individuals who report small behavioral changes, although they have not reached the criteria of effective action. We included Prochaska's precontemplation and contemplation stages as part of the preparation variation. The "action" variation involves overt behavioral changes since clinicians have faced teaching responsibilities. Their intentions were directed to influence student's life through varied activities directed by the learning and teaching conceptions that support their teaching. Analyzing the change process of clinicians, we took into consideration the statements from the categories teacher's mood and satisfaction source.

We observed that the educational journey starts with awareness of some particular aspects unique to teaching that contrast with clinical practice; then, it shifts to make a decision to change, accompanied by the planning and creation of educational activities aligned with the new concept. Neese described 
her transformational journey from clinician to educator, as a trip with an ultimate destination determined fully or partly by the learner. ${ }^{20}$ Recognizing that the energy required for the trip results from feelings and rewards, we explored these aspects with teacher's mood and satisfaction source categories. The teacher mood as a set of feelings has been powerfully related to many meaningful educational outcomes such as teacher persistence, enthusiasm, commitment, and instructional behavior, as well as student outcomes such as achievement, motivation, and self-efficacy beliefs. ${ }^{18}$ Satisfaction source is grounded on critical concepts such as the capability to attain goals and willingness to work as hard as needed in spite of difficult circumstances, in light of community recognition. ${ }^{12}$

It was possible to identify four patterns in the ways of experiencing the educational journey, which were represented by a combination of related critical aspects and categories that were simultaneously present in a person's focal awareness. Marton and Booth explored focal awareness stating that when a teacher becomes aware that teaching is done in a certain way, then he/she also becomes aware that it could be done in another way. ${ }^{12}$ The journey was fed by attitudes and motivations arising from the intention to achieve better results as well as from feelings of satisfaction and rewards from internal or external sources. Participants could be at different points on this journey, but it was possible to identify variations in focus, strategies, and actions in doing teaching related to the two themes claimed by this study. There were teaching strategies that ranged from student-centered to teacher-centered and actions that ranged from intentions to overt change of actions.

The outcome in this phenomenographic study is represented analytically as ways of experiencing the journey of clinicians to become medical teachers. It constitutes a description of the phenomenon, as it was experienced by medical practitioners. ${ }^{21}$ Phenomenography sets out to reveal the different ways in which people experience the same phenomena in the same situation. Situation and the phenomena are inextricably intertwined in the experience. In our study, the journey was conceived as phenomena that conferred sense to the teaching situation. Phenomena consist of two main aspects: the direction in terms of the "what," as a search for building up a new identity as educator, and the "how," as an identification of the source of energy for this changing process. In directing toward a new identity as educators, clinicians need to be aware of the need to transfer the focus of their teaching activities to students and to acknowledge the influence of details of the environment that affect teaching. ${ }^{16,22}$ Those who succeed in this transformation might be able to facilitate learning using a student-centered strategy.
This study has identified an outcome space that describes and relates some categories and themes clinicians have used in coping with their role as teachers. A phenomenographic approach directs attention to aspects teachers acknowledge as important to teaching and to their experience as educators. Experience in this approach is situated in a broad context that includes thoughts, memories, emotions, and expectations elicited in the teacher. ${ }^{23}$ As far as the present study is concerned, when the clinician experiences teaching, he/she does it as an expression of an interaction between the teacher and the teaching itself. Our study serves as a foundation to build upon in medical education. We consider that a shift in teacher perspective from knowledge acquisition and transmission to facilitation of transformation processes from clinician to educator is essential. This requires a drastic change in paradigm, shifting teachers' conceptions as human beings, centering the object in human interaction as a key element in the process of learning.

New fields of research are now open to studies aimed at exploring not only the teaching and learning activity itself, but also the effects on the teacher's world and how they attain awareness about different aspects relevant to make learning possible. Exploring the transformational process physicians should use to do teaching implies identifying ways of doing the tasks and conceptions they bring to learning environments as well as a deep understanding of the concept of approaches to learning and teaching. Further research questions to be explored include the following: How do labor conditions influence the transformation of clinician into medical teacher? Are all physicians who have educational responsibilities aware of the need of transformation? And what is the relationship between increasing pedagogical knowledge in clinicians and their transformation to medical educators?

\section{Author contributions}

Both authors contributed toward data analysis, drafting and critically revising the paper, gave final approval of the version to be published, and agree to be accountable for all aspects of the work.

\section{Disclosure}

The authors report no conflicts of interest in this work.

\section{References}

1. Kember D, Kwan KP. Lecturers' approaches to teaching and their relationship to conceptions of good teaching. Instr Sci. 2000;28(5):469-490.

2. Trigwell K, Prosser M, Taylor P. Qualitative differences in approaches to teaching first year university science. High Educ. 1994;27:75-84.

3. Knowles MS. Andragogy, not pedagogy. Adult Leadership. 1968;16(10): 350-352, 386. 
4. Knowles MS. The Modern Practice of Adult Education: From Pedagogy to Andragogy. 2nd ed. New York: Cambridge Books; 1980.

5. Dimitroff A, Davis WK. Content analysis of research in undergraduate medical education. Acad Med. 1996;71:60-67.

6. Tiberius RG, Sinai J, Flak EA. The role of teacher-learners relationship in medical education. In: Geoff N, Cees V, Newble D, editors. International Handbook of Research In Medical Education. Dordrecht, The Netherlands: Kluwer Academic Publisher; 2002:462-498.

7. Steinert Y. Staff development for clinical teachers. The Clinical Teacher. 2005;2:105-109.

8. Seabrook MA. Medical teachers' concerns about the clinical teaching context. Med Educ. 2003;37:213-222.

9. Lowry, S. Trends in health care and their effects on medical education. BMJ. 1993;306:255-262.

10. Arguello-Ospina A, Sandoval-Garcia C. El sistema de educación médica en Colombia: cien años de atraso [Colombian medical education system: a hundred years behind]. Rev Cienc Salud. 2006;4:73-81. Spanish.

11. Bitten N. Qualitative research: qualitative interview in medical research BMJ. 1995;311:251-253.

12. Marton F, Booth S. Learning and Awareness. Hillsdale, NJ: Lawrence Erlbaum; 1997.

13. Pang MF. Two faces of variation on continuity in the phenomenographic movement. Scand J Educ Res. 2003;47(2):145-156.
14. Starr S, Ferguson WJ, Haley HL, Quirk M. Community preceptors' views of their identities as teachers. Acad Med. 2003;78:820-825.

15. Irby DM. What clinical teachers in medicine need to know. Acad Med. 1994;69:333-342.

16. Biggs J. Teaching for Quality Learning at University. 2nd ed. Buckingham: SRHE and Open University press; 2003.

17. Starr S, Haley HL, Mazor KM, Ferguson W, Philbin M, Quirk M. Initial testing of an instrument to measure teachers identity on physicians. Teach Learn Med. 2006;18:117-125.

18. Stone S, Ellers B, Holmes D, Orgren R, Qualters D, Thompson J. Identifying oneself as a teacher: the perceptions of preceptors. Med Educ. 2002;36:180-185

19. Prochaska J, DiClemente C, Norcross J. In search of how people change. Application to addictive behavior. Am Psychol. 1992;47:1102-1114.

20. Neese R. A transformational journey from clinician to educator. J Contin Educ Nurs. 2003;34:258-262.

21. Prosser M. Phenomenography and the principles and practices of learning. High Educ Res Develop. 2006;12(1):21-31.

22. Martin E, Prosser M, Trigwell K, Ramsden P, Benjamin J. What university teachers teach and how they teach it. Instr Sci. 2000;28: $387-412$.

23. Alexandersson M. Method and Consciousness [Dissertation]. Goteborg: Acta Univertsitatis Gothoburgensis; 1994
Advances in Medical Education and Practice

\section{Publish your work in this journal}

Advances in Medical Education and Practice is an international, peerreviewed, open access journal that aims to present and publish research on Medical Education covering medical, dental, nursing and allied health care professional education. The journal covers undergraduate education, postgraduate training and continuing medical education

\section{Dovepress}

including emerging trends and innovative models linking education, research, and health care services. The manuscript management system is completely online and includes a very quick and fair peer-review system. Visit http://www.dovepress.com/testimonials.php to read real quotes from published authors. 